\title{
Two Genetically Distinct Plasmodium knowlesi Duffy Binding Protein Alpha Region II (PkDBPall) Haplotypes Demonstrate Higher Binding Level to Fy $(a+b+)$ Erythrocytes than Fy(a+b-) Erythrocytes
}

\author{
Chin Chin Liew, ${ }^{1}$ Yee Ling Lau, ${ }^{2}$ Mun Yik Fong, ${ }^{2}$ and Fei Wen Cheong ${ }^{2 *}$ \\ ${ }^{1}$ Department of Biomedical Science, Faculty of Medicine, University of Malaya, Kuala Lumpur, Malaysia; ${ }^{2}$ Department of Parasitology, Faculty of \\ Medicine, University of Malaya, Kuala Lumpur, Malaysia
}

\begin{abstract}
Invasion of human erythrocytes by merozoites of Plasmodium knowlesi involves interaction between the P. knowlesi Duffy binding protein alpha region II (PkDBPall) and Duffy antigen receptor for chemokines (DARCs) on the erythrocytes. Information is scarce on the binding level of PkDBPall to different Duffy antigens, Fy ${ }^{\mathrm{a}}$ and Fy ${ }^{\mathrm{b}}$. This study aims to measure the binding level of two genetically distinct PkDBPall haplotypes to Fy(a+b-) and Fy(a+b+) human erythrocytes using erythrocyte-binding assay. The binding level of PkDBPall of Peninsular Malaysian and Malaysian Borneon haplotypes to erythrocytes was determined by counting the number of rosettes formed in the assay. Overall, the Peninsular Malaysian haplotype displayed higher binding activity than the Malaysian Borneon haplotype. Both haplotypes exhibit the same preference to $\mathrm{Fy}(\mathrm{a}+\mathrm{b}+)$ compared with $\mathrm{Fy}(\mathrm{a}+\mathrm{b}-)$, hence justifying the vital role of $\mathrm{Fy}^{\mathrm{b}}$ in the binding to PkDBPall. Further studies are needed to investigate the $P$. knowlesi susceptibility on individuals with different Duffy blood groups.
\end{abstract}

Plasmodium knowlesi, the fifth human malaria parasite, has been reported to cause infections in many of the Southeast Asian countries in recent years. In Malaysia, the burden of $P$. knowlesi cases has surpassed those of Plasmodium vivax, thus acknowledged as the main cause of human malaria in the country. ${ }^{1}$

The asexual multiplication of $P$. knowlesi relies on the invasion of its merozoites into human erythrocytes involving a complex molecular interaction between $P$. knowlesi Duffy binding protein alpha (PkDBPa) and the Duffy antigen receptor for chemokines (DARCs) on human erythrocytes, which serve as the ligand and the receptor, respectively. ${ }^{2}$ $P$. knowlesi Duffy binding protein alpha, a large protein that consists of seven regions (I-VII), has its binding domains found in the cysteine-rich region $\mathrm{Il}^{3}$ therefore, the binding domain is termed as $P$. knowlesi Duffy binding protein alpha region II (PkDBPall).

Plasmodium knowlesi Duffy binding protein alpha region II isolates from Malaysia were found to be genetically distinct based on geographical separation (Peninsular Malaysia and Malaysian Borneo), following the discovery of genetic diversity among PkDBPall isolates. ${ }^{4,5}$ The inability of $P$. knowlesi to invade human erythrocytes without Duffy determinants affirms the role of DARCs as the obligate receptor for $P$. knowlesi. ${ }^{6}$ The two immunologically distinct human erythrocyte Duffy antigens, $\mathrm{Fy}^{\mathrm{a}}$ and $\mathrm{Fy}^{\mathrm{b}}$, are encoded by alleles that follow codominant inheritance. This gives rise to four Duffy phenotypes, Fy(a+b-), Fy(a-b+), Fy(a+b+), and Fy(a-b-). ${ }^{7}$ Generally, $\mathrm{Fy}(\mathrm{a}+\mathrm{b}-)$ is primarily found in Peninsular Malaysia, whereas $\mathrm{Fy}(\mathrm{a}+\mathrm{b}+)$ predominates in indigenous population originating from Malaysian Borneo. ${ }^{8}$

Apart from $P$. knowlesi, $P$. vivax also uses the Duffy receptor on erythrocytes to mediate invasion. It has been noticed that the Duffy binding protein region II of $P$. vivax (PvDBPII) has a higher binding level to $\mathrm{Fy}^{\mathrm{b}}$ than $\mathrm{Fy}^{\mathrm{a}}$. Moreover, the lower

\footnotetext{
${ }^{*}$ Address correspondence to Fei Wen Cheong, Department of Parasitology, Faculty of Medicine, University of Malaya, Jalan Universiti, Kuala Lumpur 50603, Malaysia. E-mail: fwcheong18@ um.edu.my
}

binding level to $\mathrm{Fy}^{\mathrm{a}}$ correlates with a lower risk to acquire clinical vivax malaria. ${ }^{9}$ This had stimulated the interest in PkDBPall, which strictly relies on Duffy antigens for merozoite invasion into human erythrocytes. To date, comparative studies on the binding of PkDBPall to different Duffy blood phenotypes are lacking.

Although $P$. knowlesi infection is widespread across all Southeast Asian countries, its exceptionally high burden in Malaysian Borneo is rather puzzling. With the ubiquity of $\mathrm{Fy}(\mathrm{a}+\mathrm{b}+)$ blood group in Malaysian Borneo, the Duffy antigen difference may have a significant role in influencing the binding of PkDBPall to erythrocytes. The aim of this study was to measure and compare the binding level of human Fy(a+b-) and $\mathrm{Fy}(\mathrm{a}+\mathrm{b}+)$ erythrocytes to two genetically distinct PkDBPall haplotypes.

The use of human blood samples in the present study was approved by the University of Malaya Medical Centre Medical Ethics Committee (MEC Ref. No.: 817.17). Individuals with blood group phenotypes $\mathrm{Fy}(\mathrm{a}+\mathrm{b}-)$ and $\mathrm{Fy}(\mathrm{a}+\mathrm{b}+)$ were recruited to participate in this study ( $n=4$ for each Duffy blood group). These individuals consented to participate in this study. Duffy group genotyping was conducted using allelespecific PCR based on the method described previously with the primers in Table $1 .{ }^{10}$

Two PkDBPall recombinant protein constructs representing the most prevalent haplotype in Peninsular Malaysia and Malaysian Borneo, respectively, were obtained from a previous study by Lim et al. ${ }^{11}$ Haplotypes $\mathrm{H} 2$ and $\mathrm{H} 47$ were selected as representative for Peninsular Malaysia and Malaysian Borneo, respectively. Haplotype $\mathrm{H} 2$ has the highest frequency (19/60) among PkDBPall sequences from Peninsular Malaysian isolates, ${ }^{5}$ whereas haplotype $\mathrm{H} 47$ has the highest frequency (10/49) among PkDBPall sequences from Malaysian Borneon isolates. ${ }^{4}$ The PkDBPall recombinant proteins were expressed on the surface of COS-7 $\left(\right.$ ATCC $^{\circledR}$ CRL-1651 ${ }^{\mathrm{TM}}$ ) mammalian cells. Protein expression and erythrocyte-binding assays were performed as previously described. ${ }^{11,12}$ The binding level of PkDBPall haplotypes to erythrocytes was determined by counting the number of rosettes formed in the assay. COS-7 cells transfected with 
TABLE 1

Primers for Duffy group genotyping

\begin{tabular}{ll}
\hline Name of the primer & \multicolumn{1}{c}{ Primer sequence $\left(5^{\prime} \rightarrow 3^{\prime}\right)$} \\
\hline FY_forward & CCCTCATTAGTCCTTGGCTCTTCT \\
FY*A_reverse & CAGCTGCTTCCAGGTTGGCTC \\
FY*B_reverse & CAGCTGCTTCCAGGTTGGCTT \\
FY*BES_forward & CCCTCATTAGTCCTTGGCTCTTTC \\
\hline
\end{tabular}

pDisplay-AcGFP1 without $P$ kDBPall gene (empty vector), and non-transfected COS-7 cells were used as negative controls. All erythrocyte-binding assays were technically duplicated.

Statistical analysis was performed using SPSS (ver. 20) statistical software (IBM Corp., Chicago, IL). Separate independent $t$-test analysis was applied to the two PkDBPall haplotypes to compare the mean difference between the binding level (rosettes formation) of $\mathrm{Fy}(\mathrm{a}+\mathrm{b}-)$ and $\mathrm{Fy}(\mathrm{a}+\mathrm{b}+)$ erythrocytes to PkDBPall. A $P$-value less than 0.05 indicates a significant difference.

In this study, a higher binding level was observed in $\mathrm{Fy}(\mathrm{a}+\mathrm{b}+)$ than $\mathrm{Fy}(\mathrm{a}+\mathrm{b}-)$ erythrocytes in both haplotypes (Figure 1). The numbers of rosettes formed in the Peninsular Malaysian haplotype (with both Fy[a+b-] and Fy[a+b+]) were higher than those in the Malaysian Borneon haplotype (with both $\mathrm{Fy}[\mathrm{a}+\mathrm{b}-]$ and $\mathrm{Fy}[\mathrm{a}+\mathrm{b}+])$. For the Peninsular Malaysian haplotype, the number of rosettes formed (mean \pm SD) with $\mathrm{Fy}(\mathrm{a}+\mathrm{b}-)$ and $\mathrm{Fy}(\mathrm{a}+\mathrm{b}+)$ erythrocytes was $27.00 \pm 4.97$ and $65.00 \pm 17.32$, respectively $(P=0.006)$. When assayed with the Malaysian Borneon haplotype, $3.50 \pm 1.91$ and $26.00 \pm 10.42$ rosettes were obtained for $\mathrm{Fy}(\mathrm{a}+\mathrm{b}-)$ and $\mathrm{Fy}(\mathrm{a}+\mathrm{b}+)$ erythrocytes, respectively $(P=0.021)$ (Table 2$)$. The rosette number difference observed for Fy(a+b-) and Fy(a+b+) erythrocytes was significant for both haplotypes. For the Peninsular Malaysian haplotype, the number of rosettes formed in $\mathrm{Fy}(\mathrm{a}+\mathrm{b}+)$ was 2.4-fold higher than that formed in Fy(a+b-), whereas for the Malaysian Borneon haplotype, the number of rosettes observed in $\mathrm{Fy}(\mathrm{a}+\mathrm{b}+)$ was 7.4 -fold higher than that observed in Fy(a+b-) erythrocytes. Meanwhile, no rosettes were observed in negative controls.

The interaction between PkDBPall and Duffy antigen on the surface of erythrocytes is a crucial step in the invasion of $P$. knowlesi merozoites for asexual multiplication. In the present study, a significant difference was observed between the binding of PkDBPall to different Duffy groups. A higher binding level was observed between PkDBPall and $\mathrm{Fy}(\mathrm{a}+\mathrm{b}+)$ erythrocytes compared with $\mathrm{Fy}(\mathrm{a}+\mathrm{b}-)$. This binding pattern was found to be consistent in both Peninsular Malaysian and Malaysian Borneon haplotypes. This phenomenon is similar to that observed between PVDBPII and human erythrocytes.

The entry of $P$. vivax into host erythrocytes is almost solely dependent on the Duffy pathway, ${ }^{13}$ although recent studies reported some vivax malaria cases in Duffy-negative individuals. ${ }^{14-16}$ Nonetheless, PvDBPII still remains as one of the most important binding proteins for $P$. vivax invasion. In a comparative study, PvDBPIl was shown to exhibit higher binding to $\mathrm{Fy}^{\mathrm{b}}$ than $\mathrm{Fy}^{\mathrm{a}}$. The researchers also found that individuals with $\mathrm{Fy}(\mathrm{a}+\mathrm{b}-)$ erythrocytes correlate to $30-80 \%$ reduced risk of acquiring uncomplicated clinical vivax malaria, as compared with those with $\mathrm{Fy}(\mathrm{a}-\mathrm{b}+)^{9}{ }^{9}$

Plasmodium knowlesi Duffy binding protein alpha region II and PvDBPII are orthologous binding proteins with identical amino acid residues in the binding domain (Tyr94, Asn95,
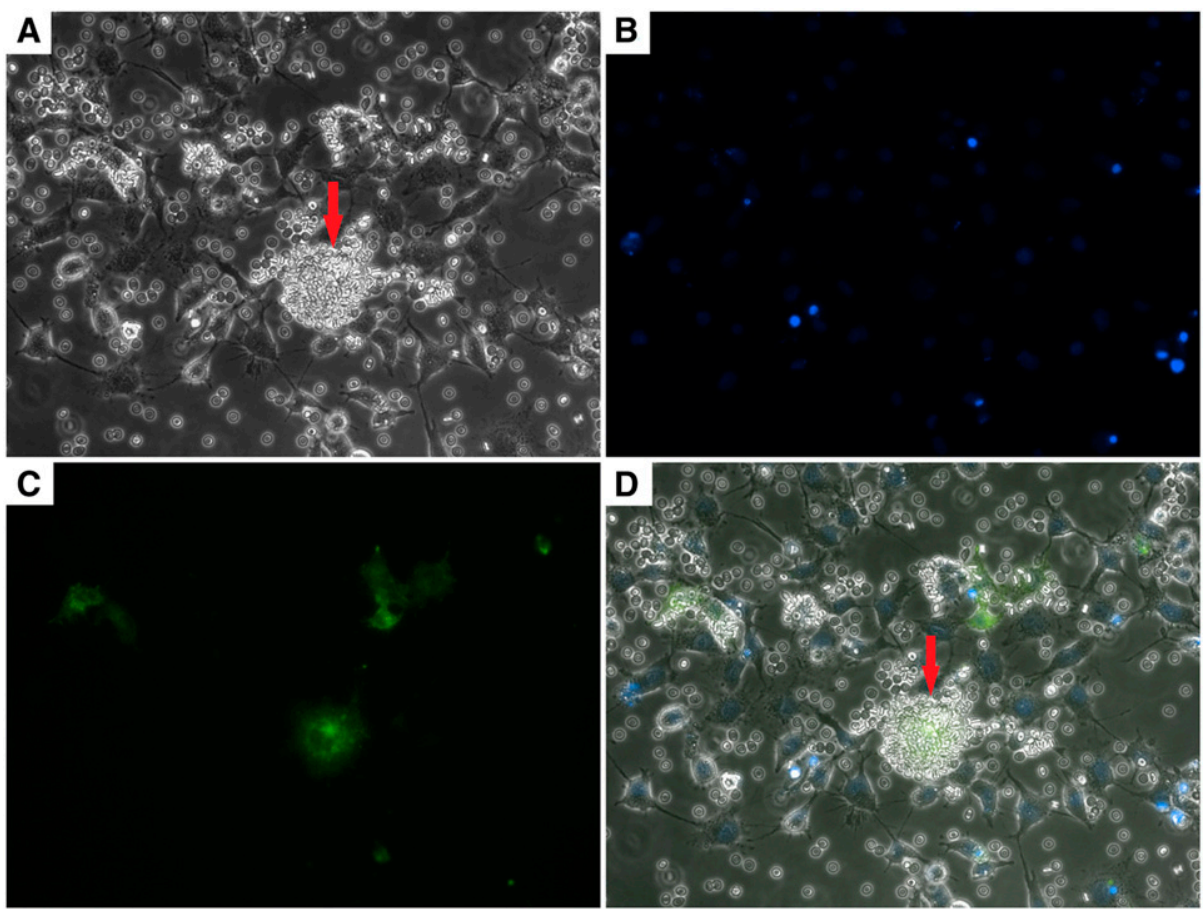

FIGURE 1. Erythrocyte-binding assay to assess the binding level of Plasmodium knowlesi Duffy binding protein alpha region II (PkDBPall) to erythrocytes. (A) Formation of rosette showing erythrocytes covering more than $50 \%$ surface of COS-7 cell transfected with recombinant PkDBPall (red arrow). (B) Cell nuclei stained with Hoechst dye were seen as blue fluorescence under 4',6-diamidino-2-phenylindole filter. (C) Transfected COS-7 cells emitted green fluorescence under FITC filter, indicating expression of GFP tag cloned to C-terminal of PkDBPall. (D) Merged image of A-C showing the location of rosette, stained nuclei, and transfected cells. This figure appears in color at www.ajtmh.org. 
TABLE 2

Erythrocyte-binding assays of Peninsular Malaysian and Malaysian Borneon Plasmodium knowlesi Duffy binding protein alpha region II (PkDBPall) haplotypes using Fy $(\mathrm{a}+\mathrm{b}-)(n=4)$ and $\mathrm{Fy}(\mathrm{a}+\mathrm{b}+)(n=4)$ erythrocytes

\begin{tabular}{lrr}
\hline & \multicolumn{2}{c}{ No. of rosettes (mean \pm SD) } \\
\cline { 2 - 3 } Haplotypes of PkDBPall & Blood phenotype Fy(a+b-) & Blood phenotype Fy(a+b+) \\
\hline Peninsular Malaysia & $27.00 \pm 4.97$ & $65.00 \pm 17.32$ \\
Malaysian Borneo & $3.50 \pm 1.91$ & $26.00 \pm 10.42$ \\
\hline${ }^{*} P<0.05$ is considered statistically significant. & 0.006 \\
\end{tabular}

Lys96, Arg103, Leu168, and Ile175). ${ }^{17}$ These binding residues are essential in the binding to Duffy determinants on erythrocytes as domain deletion abolishes PkDBPall-DARC interaction. ${ }^{18}$ Hence, PkDBPall and PvDBPII demonstrate a similar preference to erythrocytes that express $\mathrm{Fy}^{\mathrm{b}}$ antigens.

The higher binding level of PkDBPall to $\mathrm{Fy}(\mathrm{a}+\mathrm{b}+)$ than $\mathrm{Fy}(\mathrm{a}+\mathrm{b}-)$ erythrocytes is likely attributed to the pressure of $\mathrm{Fy}^{\mathrm{b}}$ antigen on the $\mathrm{Fy}(\mathrm{a}+\mathrm{b}+)$ erythrocyte surfaces. The amino acid substitution of Asp42 in Fy by Gly42 in Fy ${ }^{\mathrm{a}}$ as a result of single nucleotide polymorphism gives rise to the immunological difference between the two Duffy antigens. ${ }^{19}$ Because the binding of PkDBPall to the Duffy receptor is mediated by electrostatic interactions, ${ }^{20}$ the single amino acid difference between $\mathrm{Fy}^{\mathrm{a}}$ and $\mathrm{Fy}^{\mathrm{b}}$ may confer some changes in the binding ability of antigens, as Asp42 ( $\mathrm{pl}=3.2)$ in $\mathrm{Fy}^{\mathrm{b}}$ is more negatively charged than the isoelectrically neutral Gly42 ( $\mathrm{pl}=6)$ in $\mathrm{Fy}^{\mathrm{a}}{ }^{9}$.

Recently, a similar study investigating the binding activity of $\mathrm{Fy}(\mathrm{a}+\mathrm{b}-)$ and $\mathrm{Fy}(\mathrm{a}+\mathrm{b}+)$ erythrocytes to PkDBPall using erythrocyte-binding assays was reported. ${ }^{12}$ Likewise, a higher binding level to PkDBPall was demonstrated by $F y(a+b+)$ than $\mathrm{Fy}(\mathrm{a}+\mathrm{b}-)$. However, the study used only one PkDBPall haplotype. $^{12}$ In the present study, both Peninsular Malaysian and Malaysian Borneon haplotypes of PkDBPall were used. ${ }^{4}$ The two geographically distinct haplotypes were observed to display different binding levels and activity to human erythrocytes. ${ }^{11}$ Among the six amino acid residues (Y94, N95, K96, R103, L168, and I175) that are crucial for PkDBPall-Duffy binding, all but one was conserved. The amino acid substitution occurs at position 95, in which asparagine $(\mathrm{N})$ was substituted with aspartate (D) in the Malaysian Borneon haplotype. Other than N95D, a total of 11 other amino acid differences between Peninsular Malaysian and Malaysian Borneon PkDBPall were present. It is plausible that the amino acid variations confer some changes on the 3D-conformation structure on the binding protein, thus affecting the binding ability of Malaysian Borneon PkDBPall to Duffy antigens. ${ }^{11}$ Regardless of their difference in terms of binding ability to the Duffy antigen, PkDBPall of both haplotypes demonstrated a higher binding level to $\mathrm{Fy}(\mathrm{a}+\mathrm{b}+)$ than $\mathrm{Fy}(\mathrm{a}+\mathrm{b}-)$ in the present study. With the same preference to $\mathrm{Fy}(\mathrm{a}+\mathrm{b}+)$ observed in both the haplotypes, the vital role of $\mathrm{Fy}^{\mathrm{b}}$ in the binding to PkDBPall is justified.

In conclusion, $\mathrm{Fy}(\mathrm{a}+\mathrm{b}+)$ had a significantly higher binding level to PkDBPall than Fy(a+b-). The same binding trend to $\mathrm{Fy}(\mathrm{a}+\mathrm{b}+)$ erythrocytes was observed for both the Peninsular Malaysian and Malaysian Borneon haplotypes of PkDBPall. Hence, it was deduced that amino acid difference between $\mathrm{Fy}^{\mathrm{a}}$ and $\mathrm{Fy}^{\mathrm{b}}$ has a role in causing the different binding levels to PkDBPall. Further studies should be performed to investigate the knowlesi infection susceptibility on individuals with different Duffy blood groups.
Received November 8, 2019. Accepted for publication January 6, 2020.

Published online March 16, 2020.

Financial support: This study was supported by the Fundamental Research Grant Scheme (FRGS), FRGS/1/2018/SKK12/UM/02/1 (FP030-2018A) from the Ministry of Higher Education, Malaysia.

Authors' addresses: Chin Chin Liew, Department of Biomedical Science, Faculty of Medicine, University of Malaya, Kuala Lumpur, Malaysia, E-mail: josephineliew96@gmail.com. Yee Ling Lau, Mun Yik Fong, and Fei Wen Cheong, Department of Parasitology, Faculty of Medicine, University of Malaya, Kuala Lumpur, Malaysia, E-mails: lauyeeling@um.edu.my, fongmy@um.edu.my, and fwcheong18@um.edu.my.

\section{REFERENCES}

1. Yusof R, Lau YL, Mahmud R, Fong MY, Jelip J, Ngian HU, Mustakim S, Hussin HM, Marzuki N, Ali MM, 2014. High proportion of knowlesi malaria in recent malaria cases in Malaysia. Malar J 13: 168.

2. Chitnis CE, Miller LH, 1994. Identification of the erythrocyte binding domains of Plasmodium vivax and Plasmodium knowlesi proteins involved in erythrocyte invasion. J Exp Med 180: 497-506.

3. Adams JH, Sim B, Dolan SA, Fang X, Kaslow DC, Miller LH, 1992. A family of erythrocyte binding proteins of malaria parasites. Proc Natl Acad Sci USA 89: 7085-7089.

4. Fong MY, Rashdi SA, Yusof R, Lau YL, 2015. Distinct genetic difference between the Duffy binding protein (PkDBPall) of Plasmodium knowlesi clinical isolates from North Borneo and Peninsular Malaysia. Malar J 14: 91.

5. Fong MY, Lau YL, Chang PY, Anthony CN, 2014. Genetic diversity, haplotypes and allele groups of Duffy binding protein (PkDBPall) of Plasmodium knowlesi clinical isolates from Peninsular Malaysia. Parasit Vectors 7: 161.

6. Miller LH, Mason SJ, Dvorak JA, McGinniss MH, Rothman IK, 1975. Erythrocyte receptors for (Plasmodium knowlesi) malaria: Duffy blood group determinants. Science 189: 561-563.

7. Marsh WL, Schmidt P, 1975. Present status of the Duffy blood group system: articles reviewed. Crit Rev Clin Lab Sci 5: 387-412.

8. De Silva JR, Amir A, Lau YL, Ooi CH, Fong MY, 2019. Distribution of the Duffy genotypes in Malaysian Borneo and its relation to Plasmodium knowlesi malaria susceptibility. PLoS One 14: e0222681.

9. King CL et al., 2011. Fya/Fyb antigen polymorphism in human erythrocyte Duffy antigen affects susceptibility to Plasmodium vivax malaria. Proc Natl Acad Sci USA 108: 20113-20118.

10. Cotorruelo C, Biondi C, Racca L, Borrás SG, Racca A, 2009. Duffy genotyping facilitates transfusion therapy. Clin Exp Med 9: 249-251.

11. Lim KL, Amir A, Lau YL, Fong MY, 2017. The Duffy binding protein (PkDBPall) of Plasmodium knowlesi from Peninsular Malaysia and Malaysian Borneo show different binding activity level to human erythrocytes. Malar J 16: 331.

12. Fong MY, Cheong FW, Lau YL, 2018. Erythrocyte-binding assays reveal higher binding of Plasmodium knowlesi Duffy binding protein to human Fy $a+/ b+$ erythrocytes than to $F y ~ a+/ b-$ erythrocytes. Parasit Vectors 11: 527.

13. Miller LH, Mason SJ, Clyde DF, McGinniss MH, 1976. The resistance factor to Plasmodium vivax in blacks: the Duffy-bloodgroup genotype, FyFy. N Engl J Med 295: 302-304. 
14. Ryan JR et al., 2006. Evidence for transmission of Plasmodium vivax among a Duffy antigen negative population in Western Kenya. Am J Trop Med Hyg 75: 575-581.

15. Cavasini CE, Mattos LC, Couto AA, Bonini-Domingos CR, Valencia SH, Neiras WC, Alves RT, Rossit AR, Castilho L, Machado RL, 2007. Plasmodium vivax infection among Duffy antigen-negative individuals from the Brazilian Amazon region: an exception? Trans R Soc Trop Med Hyg 101: 1042-1044.

16. Ménard D et al., 2010. Plasmodium vivax clinical malaria is commonly observed in Duffy-negative Malagasy people. Proc NatI Acad Sci USA 107: 5967-5971.

17. Singh SK, Hora R, Belrhali H, Chitnis CE, Sharma A, 2006. Structural basis for Duffy recognition by the malaria parasite Duffy-binding-like domain. Nature 439: 741-744.
18. Singh SK, Singh AP, Pandey S, Yazdani SS, Chitnis CE, Sharma A, 2003. Definition of structural elements in Plasmodium vivax and $P$. knowlesi Duffy-binding domains necessary for erythrocyte invasion. Biochem J 374: 193198.

19. Tournamille C, Le Van Kim C, Gane P, Cartron J-P, Colin Y, 1995. Molecular basis and PCR-DNA typing of the Fya/fyb blood group polymorphism. Hum Genet 95: 407-410.

20. Ntumngia FB, Thomson-Luque R, Pires CV, Adams JH, 2016. The role of the human Duffy antigen receptor for chemokines in malaria susceptibility: current opinions and future treatment prospects. J Receptor Ligand Channel Res 9: $1-11$. 